\title{
U.S. Policy Considerations for Telehealth Provision in Audiology
}

\author{
Anna Marie Jilla, Au.D., Ph.D., ${ }^{1}$ Michelle L. Arnold, Au.D., Ph.D., ${ }^{2}$ and \\ Erin L. Miller, Au.D. ${ }^{3}$
}

ABSTRACT

The demand for telehealth services will continue to grow alongside an increased need for audiology services among both children and adults. Insurance coverage policies for audiologic services are specific to each payer and vary widely in the level of coverage provided for both in-person and telehealth-based audiology services. While benefits for children are fairly comprehensive, coverage for audiology services for adults is generally poor. Traditional Medicare does not cover hearing aids or other rehabilitative audiologic services, and other payer policies vary widely. Lack of benefits for hearing and balance services is inconsistent with the evidence base and leaves many beneficiaries without access to meaningful care for hearing and balance disorders, which are highly prevalent among and disproportionately affect Medicare beneficiaries. The purpose of this article is to discuss regulatory and reimbursement considerations for telehealth provision in audiology and elucidate opportunities to influence related health policy at both state and federal levels.

KEYWORDS: telehealth, audiology, health policy, health insurance, licensure

\footnotetext{
Audiologic services promote better health, well-being, and quality of life across the lifespan. ${ }^{1-3}$ The need for hearing and balance care continues to increase for Americans, especially in view of the growing demographic of older adults, ${ }^{4}$ as this population is

${ }^{1}$ Department of Otorhinolaryngology - Head and Neck Surgery, University of Texas Health Science Center at Houston, Houston, Texas; ${ }^{2}$ Department of Communication Sciences and Disorders, University of South Florida Sarasota-Manatee Campus, Sarasota, Florida; ${ }^{3}$ School of Speech-Language Pathology and Audiology, The University of Akron, Akron, Ohio.

Address for correspondence: Anna Marie Jilla, Au.D., Ph.D., Department of Otorhinolaryngology - Head and Neck Surgery, University of Texas Health Science Center at
}

highly likely to experience age-related hearing loss ${ }^{5,6}$ and vestibular disorders. ${ }^{7}$ Yet in the United States, most insurance plans and Medicare Part B (traditional Medicare) do not cover the majority of hearing or balance-related rehabilitative services that can result in improved

Houston, 6400 Fannin Street, Suite 2700, Houston, TX 77030 (e-mail: Anna.Jilla@gmail.com).

Expanding and Enhancing Care with Tele-Audiology; Guest Editor, Lori Zitelli, Au.D., CH-TM

Semin Hear 2021;42:165-174. (C) 2021. Thieme. All rights reserved. Thieme Medical Publishers, Inc., 333 Seventh Avenue, 18th Floor, New York, NY 10001, USA DOI: https://doi.org/10.1055/s-0041-1731697.

ISSN 0734-0451. 
quality of life. Non-coverage determinations also apply to telehealth provisions. The hearing and balance coverage chasm constitutes a significant barrier for timely access to care, leaving beneficiaries with little financial assistance to address their hearing and balance care needs.

In the United States, a quarter of adults aged 60 to 69 years and over $50 \%$ of those aged 70 to 79 years have clinically significant hearing loss. ${ }^{8}$ Hearing impairment has been identified as the primary modifiable mid-life risk factor for dementia, accounting for a greater proportion of risk than both smoking and education. ${ }^{9,10}$ Untreated hearing loss also is associated with increased risk of social isolation, ${ }^{11}$ depression, ${ }^{12}$ falls, ${ }^{13}$ hospitalizations, ${ }^{14}$ and adverse events. ${ }^{15}$ Hearing loss is the fifth most common cause of years lived with a disability $^{16}$ and largely remains unaddressed as a chronic health concern by most insurers in the United States. ${ }^{17,18}$

Prevalence of hearing loss among children is also common. Two out of every 1,000 infants are born with a hearing loss ${ }^{19}$ and $12 \%$ of children aged 6 to 19 years have a hearing loss due to noise exposure from listening to excessively loud music through headphones. ${ }^{20}$ Unaddressed hearing loss among children can lead to lower academic achievement ${ }^{21}$ and poorer literacy outcomes, ${ }^{22}$ as well as lower earnings and higher risk for un- or underemployment in adulthood. ${ }^{23,24}$ The per person societal costs of childhood hearing loss are estimated to be $\$ 1$ million and include costs related to lost productivity, increased health care expenditures, educational support, and societal costs of stigmatization of hearing loss. ${ }^{25}$

It is estimated that $35 \%$ of Americans 40 years and older have vestibular dysfunction, which remains a large public health concern, particularly among older adults. ${ }^{7}$ Vestibular dysfunction contributes to falls which in turn can result in injury, hospitalizations, and restricted mobility. ${ }^{26}$ The annual cost of nonfatal falls reached $\$ 55$ billion in the United States in $2020 .{ }^{27}$ Individuals with vestibular dysfunction are at a 2.6-fold increased risk for falls, increasing to 12 -fold risk when clinically symptomatic. $^{7}$ Delayed access to balance care can also increase associated health care costs; an average of 4.5 physician visits are conducted before reaching diagnosis for balance disorders ${ }^{28}$ and the average time between onset to diagnosis for some vestibular disorders is as high as 740 days. ${ }^{29}$ These inefficiencies in access to balance care often result in unnecessary expenditures for testing and ineffective therapy (e.g., magnetic resonance imaging, overuse of repositioning maneuvers, or laboratory work). Perhaps unsurprisingly, U.S. referral rates for dizziness stay low at $9 \% .{ }^{30}$

The modest size and uneven geographic dispersion of the audiology workforce ${ }^{31}$ in the United States leaves many individuals with poor access to hearing and balance services that could improve health. Hearing and balance issues disproportionately affect older adults, for whom mobility may also constitute a significant barrier to access. Telehealth provision in audiology provides an opportunity to increase accessibility to hearing and balance care to meet the growing need among both children and adults.

Provision of telehealth services is an evolving issue with implications for timely access to care for patients, as well as regulations and reimbursements for services provided remotely. The objective of this review is to discuss licensing, regulatory, and reimbursement considerations for telehealth provision in audiology, as well as to identify opportunities for influencing telehealth-related policy for hearing and balance care in the United States.

\section{LICENSING AND REGULATORY CONSIDERATIONS}

\section{State Licensure and Regulation}

When providing telehealth services, it is important to document patients' geographic location during the time in which telehealth services are provided. Known as the originating site, patients' location at the time of service dictates the terms of that encounter under the respective licensure laws in the state of the originating site. In other words, audiologists must have an active license in the state where the patient is initiating services. There is also a trade-off between timely access to care and the associated administrative burden and time delays for licensure application and approval. In efforts to decrease 
regulatory burden, some exceptions have been made to expedite clinicians seeking to provide health care remotely. For example, Texas has temporarily waived licensure requirement for physicians, where "episodic telemedicine medical services" can be provided by practitioners without a Texas medical license (Texas Occupations Code, $\$ 151.056$ and $\$ 172.12(\mathrm{f}))^{32}$ Certain out-of-state providers can also apply for a telehealth license in Texas. ${ }^{33}$

State law dictates scope of practice and terms of telepractice for audiologists, support staff (e.g., audiology assistants), and audiology students under clinical supervision. Since each state has different telehealth regulations and licensure laws pertaining to hearing and balance professionals, clinicians are encouraged to seek information directly from state statutes and regulatory bodies when considering scope of practice and respective telehealth terms. State code pertaining to scope and terms of practice for audiologists and related support staff is commonly provided on state government web sites for audiology regulatory boards. Useful resources for identifying current telehealth laws and proposed legislation in each state include the state look-up tool from the Center for Connected Health Policy and the telehealth law and regulation tracker maintained by the American Speech-Language-Hearing Association. ${ }^{34}$

Some state licensure boards maintain profession-specific telehealth regulations for audiologists, such as Alaska, Arkansas, Kentucky, Louisiana, Maryland, New Mexico, Ohio, Texas, and West Virginia. ${ }^{35}$ New Hampshire explicitly grants permission to conduct telehealth visits only to certain types of health care professionals, explicitly including "hearing care providers." ${ }^{36}$ Others, such as Illinois, have taken a broader legislative approach by permitting licensed health care professionals to "engage in the practice of telehealth in Illinois to the extent of his or her scope of practice as established in his or her respective licensing act consistent with the standards of care for inperson services." 37

\section{Federal Regulation}

Federal regulations also dictate terms of telehealth provision for practitioners. As outlined under the Health Insurance Portability and Accountability Act (HIPAA) of $1996^{38}$ and Health Information Technology for Economic Clinical Health (HITECH) Act of $2009,{ }^{39}$ federal law assures privacy and security of protected health information (PHI) for patients. Generally, HIPAA rules supersede state regulations unless state protections exceed those instituted through federal statute.

HIPAA regulations similarly apply to covered entities for services provided via telehealth as they would for in-person services. Risk and vulnerability assessment should be conducted to assure that protections are reasonable and appropriate. Security standards are meant to be flexible as they are applied across a variety of different health care contexts. Considerations are made for characteristics such as the size of the business, technical infrastructure and capabilities, and the costs of instituting security measures. For detailed information regarding these statutes, the reader is directed to the HIPAA Regulation Text. ${ }^{40}$ At the time of publication, certain HIPAA regulations are under non-enforcement designations due to the COVID-19 pandemic. The United States Department of Health and Human Services has also relaxed certain HIPAA requirements for telehealth provision during this public health emergency. ${ }^{41}$

Practitioners are also cautioned regarding the lack of absolute guarantees for security and privacy for services or equipment that are branded HIPAA-compliant, such as videoconferencing software platforms, electronic medical appointment scheduling and messaging services, and remote devices (e.g., blood glucose monitoring devices, accelerometers) designed to track and relay important patient health indicators to providers. While many of these products utilize appropriate protections and have features that assist in meeting compliance standards, they are not without risk for breach. Distinct legal responsibilities for covered entities and providers of HIPAA-compliant technology and equipment remain unclear. Practitioners are encouraged to scrutinize new technologies adopted for patient care which involve electronic transmission or storage of PHI. 


\section{Current Issues and Future Considerations}

There are additional ethical considerations surrounding telehealth services. Health-related services provided remotely should be comparable to those received through in-person care. It is through this ideal of comparability that many payers reimburse at the same rates for services no matter the location of their provision. Professionals are encouraged to reference their respective professional organizations' code of ethics to ensure all services, regardless of delivery method, are provided in an equitable manner. Licensure requirements and scope of practice regulations vary greatly between states, introducing potential inequities in access to hearing care, particularly in the realm of telepractice. Standardization of licensing and practice regulations, including legislature that enables licensure reciprocity across states, has potential to increase access to telehealth for millions of U.S. adults in need of hearing and balance care. Regulatory burden can impede timely access to services because of delays in obtaining and maintaining multiple licenses to provide services remotely. Facilitating licensure reciprocity rules can increase access to remote provision of hearing and balance care, particularly in areas with shortages of audiologists and related providers. Professional organizations play an important role in shaping legislature related to telehealth service provision. For example, the Audiology Speech-LanguageHearing Interstate Compact (ASLP-IC) seeks to unify occupational licensure and remove impediments to timely provision of and patients' access to care across state lines whether provided in person or via telehealth. ${ }^{42}$ The ASLP-IC needs 10 member states to initiate an interstate commission who would conceive the compact licensure rules. At the time of this writing, the ASLP-IC has gathered the necessary quorum of member states to establish the commission. ${ }^{43}$

State legislative efforts regarding telehealth provision and insurance coverage have increased in volume since the COVID-19 public health emergency. It should be noted that COVIDrelated expansions were siloed from permanent telehealth statutes in state law. At the time of this writing, it is unknown at this time whether these expansions or changes will be permanently adopted at the conclusion of this public health emergency, but high levels of satisfaction with telehealth have been uniformly reported by beneficiaries. ${ }^{44}$ Increased demand for telehealth provision by patients may force permanent adoption of certain policies by payers.

\section{REIMBURSEMENT CONSIDERATIONS}

\section{Medicare}

The Centers for Medicare and Medicaid Services (CMS) coordinates Medicare benefits for individuals with qualifying disabilities and for all Americans 65 years and older. As the largest single insurer of Americans, Medicare often serves as a model for other insurers' coverage provisions.

Medicare national coverage determinations for audiology services ${ }^{45}$ currently number fewer than 50 and are primarily constituted of diagnostic procedures, apart from coverage of cochlear implants, osseointegrated bone-conduction hearing devices, and related programming services. It is estimated that more than $75 \%$ of hearing care costs in the United States are self-pay, ${ }^{17,46}$ with an average out-of-pocket cost for services of $\$ 1,000$ plus additional costs for hearing aids, averaging $\$ 2,000$ per unit. Hearing care costs are a major access barrier for the majority of U.S. adults who could pose to benefit, considering that an out-of-pocket cost of $\$ 2,500$ would constitute a catastrophic health expense for $77 \%$ adults with serious hearing difficulty. ${ }^{47}$

Like many sectors of health care, Medicare coverage for specialized professionals is limited to a defined set of procedures. Medicare Part B (traditional Medicare) does not have coverage provisions for hearing aids, hearing aid services, audiologic rehabilitation, nonmedical management of hearing loss, vestibular dysfunction, tinnitus, or auditory processing disorders when provided by audiologists. ${ }^{45}$ Because many audiology services are not covered through Medicare Part B, non-coverage statutes also apply to coverage for telehealth services. In other words, face-to-face services not covered by Medicare Part $\mathrm{B}$ are also not covered when provided via 
telehealth. Expanded COVID-19 telehealth provisions for audiologic services were extremely limited, allowing only for coverage for cochlear implant programming services, but not for services related to any other hearing loss management or rehabilitation services. ${ }^{48}$

Other telehealth expansions during the COVID-19 emergency allowed certain providers such as nutritionists, psychologists, speechlanguage pathologists, occupational therapists, and physical therapists to transition care to telehealth and receive reimbursement for services provided remotely. ${ }^{49,50}$ These same nonphysician providers who cannot report evaluation and management $(\mathrm{E} / \mathrm{M})$ activities were also provided access to reimbursements for online assessment and management services. ${ }^{49,50}$ Because Medicare audiology benefits are considered "other diagnostic tests," the CMS could not provide audiologists access to these codes as they were not considered diagnostic. Audiologists do not typically report office or outpatient E/M services, but uniformly participate in such activities such as taking a thorough case history, evaluating and counseling the patient on findings, and developing a management plan. Reporting of $\mathrm{E} / \mathrm{M}$ services is tiered such that it also accounts for whether patients are established or new, the number and complexity of problems addressed, and work of medical decision-making.

The classification of audiologists under the Medicare program is complex. Statutory language in the Social Security Act and CMS coverage determinations for Medicare beneficiaries characterizes audiologists in a primary role as diagnosticians by way of the narrow benefit category for hearing and balance care. CMS does not currently recognize audiologists as providers of management or treatment activities, ${ }^{51}$ yet audiologists are required to report some of these activities through the CMS's Quality Payment Program Merit-based Incentive Payment Scale (MIPS), ${ }^{52}$ and they are characterized as such in CPT definitions of Medicare-covered audiology services. ${ }^{53,54}$ The nebulous classification of audiologists within Section 1861(II)(3) of the Social Security Act drives coverage determinations by CMS, as this health policy does not recognize audiologists for their full scope of practice.
CMS policy, driven by the statutory limitations within the Social Security Act, constitutes a significant access barrier for U.S. adults in need of hearing and balance care. Hearing health care access barriers could be addressed by amending language in Section 1861 of the Social Security Act to include nonmedical treatment and management under the definition of audiology services. Current legislation introduced in March 2021, H.R. 1587 Medicare Audiologist Access and Services Act of $2021,{ }^{55}$ would work to clearly define audiologists' classification. Statutory language regarding the classification of audiologists within the CMS system could also be revisited to increase access to hearing and balance care among a growing pool of Medicare beneficiaries who are disproportionately affected by hearing and balance issues. It is encouraging that increasing access to address unmet hearing health care needs of adults in the United States is gaining legislative traction.

\section{Joint Federal and State Programs: Medicaid and Children's Health Insurance Program}

Medicaid and Children's Health Insurance Program (CHIP) programs are need-based, affordable health insurance plans provided through joint efforts from federal and state governments. These plans are administered by state governments and regulated by the federal government. Unless there is a national coverage determination, coverage for hearing and balance care is defined at the state level.

Medicaid has a national coverage determination for hearing care for children, ${ }^{56}$ where states must provide beneficiaries with assessment and treatment for hearing loss, which includes hearing aids. Conversely, there is no Medicaid national coverage determination for hearing care for adults. In our own work, we found that 22 state Medicaid programs had no hearing care provisions for adults and among the 28 states with coverage, each varied widely in candidacy and coverage requirements, as well as available benefits. ${ }^{18,57}$

As Medicaid and CHIP benefits are specific to each state, telehealth regulations from these payers will also vary from state to state. 
There are some federal requirements for state Medicaid programs if they wish to change reimbursement structures for telehealth. States are obligated to submit a reimbursement state plan amendment to the CMS for approval if telehealth services are not reimbursed at the same rate as in-person services. ${ }^{58}$

Medicaid and CHIP policies regarding telehealth coverage policies for audiology services can be found on state-maintained Medicaid and CHIP Web sites, in provider bulletins, and/or by directly contacting provider relations departments. Advocacy efforts to address accessibility issues for hearing and balance care should target state legislatures and regulatory boards, as any changes would require state approval of statutory or regulatory change. ${ }^{57}$

\section{Private Insurance: Medicare Advantage, Commercial Payers, and Third-Party Networks}

Coverage policies for commercial payers and Medicare Advantage plans will vary from insurer to insurer, policy to policy. Medicare Advantage payers are contracted through CMS and plans are required by law to minimally provide all benefits available through traditional Medicare Parts A and B. ${ }^{59}$ Medicare Advantage plans vary widely in coverage policies, sometimes varying down to the zip code. Significant barriers to care still exist when coverage is provided, as many plans do not allow for provider choice, type of hearing aid, and are not transferrable to noncovered providers, even if the beneficiary was willing to make up the difference out of pocket.

Benefit information on hearing and balance care is defined in the evidence of coverage document. At the time of this writing, eight states (Arkansas, Connecticut, Illinois, Massachusetts, Maine, North Carolina, New Hampshire, and Rhode Island) have mandates requiring private insurers to cover hearing aids and associated services for at least some adults ${ }^{60,61}$; however, significant variation in coverage allowances, including telehealth reimbursement, exists between states. Patients are encouraged to contact their insurance payer's provider relations department for detailed information regarding hearing health care benefits and telehealth coverage policies for audiology services.

\section{Payer Policy Considerations}

Payer policy may have additional technological, security, and/or documentation requirements for reporting of and reimbursement for telehealth provision. Telehealth coverage may vary by communication medium. Different policies may apply for encounters conducted via videoconference (real-time audio/video), telephone call (real-time audio only), store and forward technology (asynchronous digital information or communication), or remote patient monitoring. Clinicians are encouraged to reference payer-specific policies when identifying additional reporting requirements for telehealth services.

\section{DISCUSSION}

The shift to remote service provision and telehealth has exposed accessibility issues in hearing and balance care both for children and adults in the United States. Audiologists, unlike similar nonphysician providers such as speechlanguage pathologists and physical therapists, are not reimbursed for most rehabilitative and management activities. And because audiologists are not classified as this type of provider, payers also do not reimburse audiologists for these activities when provided via telehealth. Joint state-federal insurance programs such as Medicaid and CHIP vary widely in how comprehensive the coverage policies are from state to state. Few insurers-federal, state, or private-provide coverage for certain audiologic diagnostic services (e.g., hearing aid examinations, communication/listening needs assessments) and rehabilitative services (e.g., hearing aid programming, tinnitus management, nonmedical vestibular rehabilitation).

Access barriers to hearing and balance care have potential to negatively impact population health over the lifespan. Over 60 million Americans have a clinically significant hearing loss ${ }^{6}$ and 69 million adults 40 and older exhibit a vestibular dysfunction. ${ }^{7}$ Audiologists' benefit category within the Medicare system of providers is nebulous and oftentimes contradictory. Inconsistencies and gaps in insurance coverage, including the fragmented hearing and balance care coverage for Medicare Part B beneficiaries, are poorly aligned with the evidence base which 
has demonstrated that such care is cost-effective $^{62}$; increases satisfaction with health care encounters ${ }^{63,64}$; reduces risk for undesirable health care outcomes like hospitalizations, ${ }^{14}$ readmittance, ${ }^{65}$ and adverse events ${ }^{15}$; and improves overall quality of life. ${ }^{2,3}$ Access to hearing and balance care-for services provided in person or via telehealth-may mitigate risk for and associated costs of downstream issues such as falls or dementia for older adults.

Uneven geographic distribution of audiologists also leads to large segments of the U.S. population remaining underserved. State audiology regulations are fragmented and may impede timely provision of remote services to populations in need. Telepractice represents an opportunity to increase access to hearing and balance care for these populations. Telehealth provision may indeed be the most tenable way to access hearing or balance care. Travel distance to clinics, mobility, and transportation issues are barriers to in-person care and are more commonly experienced by aging U.S. adults.

Payer policy has also lagged behind technological advancements which have reduced burdensome requirements for and costs of conducting audiologic care remotely. For example, remote programming of hearing aids is available for nearly all FDA-regulated advanced digital technology air-conduction hearing aids. Increased portability of diagnostic equipment has also made remote assessment feasible. Portable technologies for otoscopic examinations and hearing assessment are now available (e.g., app-based otoscopy kits, Shoebox audiometry). Other portions of audiologic assessment activities can be easily adopted to provision via telehealth such as gathering a focused case history, completing self-assessments or questionnaires, coordinating patient care, or counseling on findings from hearing, amplification, tinnitus, auditory processing, and vestibular assessments.

The health care community, policy makers, and beneficiaries at large should be aware of these issues that face beneficiaries with hearing and vestibular disorders. Access to timely and effective interventions may mitigate the deleterious effects of hearing and vestibular disorders, promoting health, mobility, and independence.
Legislative efforts at both federal and state levels should strive to provide beneficiaries with timely and affordable access to hearing and balance care that contributes to improvements in overall well-being and meaningful functioning and productivity within communities.

\section{CONFLICT OF INTEREST}

None declared.

\section{REFERENCES}

1. Ferguson MA, Kitterick PT, Chong LY, Edmondson-Jones M, Barker F, Hoare DJ. Hearing aids for mild to moderate hearing loss in adults. Cochrane Database Syst Rev 2017;9:CD012023

2. Chisolm TH, Johnson CE, Danhauer JL, et al. A systematic review of health-related quality of life and hearing aids: final report of the American Academy of Audiology Task Force On the Health-Related Quality of Life Benefits of Amplification in Adults. J Am Acad Audiol 2007;18(02):151-183

3. Roberts RA, Abrams H, Sembach MK, Lister JJ, Gans RE, Chisolm TH. Utility measures of healthrelated quality of life in patients treated for benign paroxysmal positional vertigo. Ear Hear 2009;30 (03):369-376

4. Ortman JM, Velkoff VA, Hogan H. An aging nation: the older population in the United States. May 2014; US Census Bureau Accessed March 15, 2021 at: https://www.census.gov/prod/2014pubs/ p25-1140.pdf

5. Lin FR, Niparko JK, Ferrucci L. Hearing loss prevalence in the United States. Arch Intern Med 2011;171(20):1851-1852

6. Goman AM, Reed NS, Lin FR. Addressing estimated hearing loss in adults in 2060. JAMA Otolaryngol Head Neck Surg 2017;143(07):733-734

7. Agrawal Y, Carey JP, Della Santina CC, Schubert MC, Minor LB. Disorders of balance and vestibular function in US adults: data from the National Health and Nutrition Examination Survey, 20012004. Arch Intern Med 2009;169(10):938-944

8. Goman AM, Lin FR. Prevalence of hearing loss by severity in the United States. Am J Public Health 2016;106(10):1820-1822

9. Livingston G, Sommerlad A, Orgeta V, et al. Dementia prevention, intervention, and care. Lancet 2017;390(10113):2673-2734

10. Livingston G, Huntley J, Sommerlad A, et al. Dementia prevention, intervention, and care: 2020 report of the Lancet Commission. Lancet 2020;396(10248):413-446 
11. Shukla A, Harper M, Pedersen E, et al. Hearing loss, loneliness, and social isolation: a systematic review. Otolaryngol Head Neck Surg 2020;162 (05):622-633

12. Rutherford BR, Brewster K, Golub JS, Kim AH, Roose SP. Sensation and psychiatry: linking agerelated hearing loss to late-life depression and cognitive decline. Am J Psychiatry 2018;175(03): 215-224

13. Jiam NTL, Li C, Agrawal Y. Hearing loss and falls: a systematic review and meta-analysis. Laryngoscope 2016;126(11):2587-2596

14. Genther DJ, Betz J, Pratt S, et al; Health, Aging and Body Composition Study. Association between hearing impairment and risk of hospitalization in older adults. J Am Geriatr Soc 2015;63(06): 1146-1152

15. Bartlett G, Blais R, Tamblyn R, Clermont RJ, MacGibbon B. Impact of patient communication problems on the risk of preventable adverse events in acute care settings. CMAJ 2008;178(12): 1555-1562

16. James SL, Abate D, Abate KH, et al; GBD 2017 Disease and Injury Incidence and Prevalence Collaborators. Global, regional, and national incidence, prevalence, and years lived with disability for 354 diseases and injuries for 195 countries and territories, 1990-2017: a systematic analysis for the Global Burden of Disease Study 2017. Lancet 2018;392(10159):1789-1858

17. Willink A, Reed NS, Swenor B, Leinbach L, DuGoff EH, Davis K. Dental, vision, and hearing services: access, spending, and coverage for Medicare beneficiaries. Health Aff (Millwood) 2020;39 (02):297-304

18. Arnold ML, Hyer K, Chisolm T. Medicaid hearing aid coverage for older adult beneficiaries: a stateby-state comparison. Health Aff (Millwood) 2017; 36(08):1476-1484

19. Vohr B. Overview: infants and children with hearing loss-part I. Ment Retard Dev Disabil Res Rev 2003;9(02):62-64

20. Niskar AS, Kieszak SM, Holmes A, Esteban E, Rubin C, Brody DJ. Prevalence of hearing loss among children 6 to 19 years of age: the Third National Health and Nutrition Examination Survey. JAMA 1998;279(14):1071-1075

21. Sarant JZ, Harris DC, Bennet LA. Academic outcomes for school-aged children with severeprofound hearing loss and early unilateral and bilateral cochlear implants. J Speech Lang Hear Res 2015;58(03):1017-1032

22. Harris M, Terlektsi E, Kyle FE. Literacy outcomes for primary school children who are deaf and hard of hearing: a cohort comparison study. J Speech Lang Hear Res 2017;60(03):701-711

23. Huddle MG, Goman AM, Kernizan FC, et al. The economic impact of adult hearing loss: a systematic review. JAMA Otolaryngol Head Neck Surg 2017; 143(10):1040-1048

24. Shan A, Ting JS, Price C, et al. Hearing loss and employment: a systematic review of the association between hearing loss and employment among adults. J Laryngol Otol 2020;134(05):387-397

25. Altman BM, Barnartt SN, Hendershot GE, et al. (Ed.). Using Survey Data to Study Disability: Results from the National Health Survey on Disability, Vol. 3. Emerald Publishing Limited, Bingley. 207-228

26. Ambrose AF, Paul G, Hausdorff JM. Risk factors for falls among older adults: a review of the literature. Maturitas 2013;75(01):51-61

27. Florence CS, Bergen G, Atherly A, Burns E, Stevens J, Drake C. Medical costs of fatal and nonfatal falls in older adults. J Am Geriatr Soc 2018;66(04):693-698

28. Luxon L. Working Party on the Provision of Audiological Medicine. Hearing and balance disorders: a new approach. Clin Med (Lond) 2007;7 (04):318-320

29. Monzani D, Casolari L, Guidetti G, Rigatelli M. Psychological distress and disability in patients with vertigo. J Psychosom Res 2001;50(06): 319-323

30. Holmes S, Padgham ND. A review of the burden of vertigo. J Clin Nurs 2011;20(19-20):2690-2701

31. Windmill IM, Freeman BA. Demand for audiology services: $30-y r$ projections and impact on academic programs. J Am Acad Audiol 2013;24(05): 407-416

32. Texas Administrative Code Title 22. Section 174.12 Accessed March 11, 2021 at: https:// www.pharmacy.texas.gov/files_pdf/BN/May14/ Tab_31.pdf

33. Out-of-State Telemedicine License. Texas Medical Board Accessed March 12, 2021 at: https:// www.tmb.state.tx.us/page/telemedicine-license

34. COVID-19: Tracking of State Laws and Regulations for Telepractice and Licensure Policy. American Speech-Language-Hearing Association. Accessed March 12, 2021 at: https://www.asha. org/siteassets/uploadedfiles/State-Telepractice-Policy-COVID-Tracking.pdf

35. Current State Laws \& Reimbursement Policies. Center for Connected Health Policy. Accessed March 12, 2021 at: https://www.cchpca.org/telehealth-policy/current-state-laws-and-reimbursement-policies

36. HB 1623-FN. State of New Hampshire. Accessed March 12, 2021 at: http://gencourt.state.nh.us/ bill_status/billText.aspx?sy=2020\&id=1180\&txt Format $=$ pdf\&v $=$ current

37. Illinois Compiled Statutes Chapter 225, 150/5. Illinois General Assembly. Accessed March 12, 2021 at: https://ilga.gov/legislation/ilcs/ilcs3.asp?ActID= 3807gov/legislation/ilcs/ilcs3.asp?ActID=3807 
38. Public Law 104-191-AUG. 21, 1996. Health Insurance Portability and Accountability Act of 1996. United States Congress Accessed March 12, 2021 at: https://www.congress.gov/104/plaws/ publ191/PLAW-104publ191.pdf

39. HITECH Act Enforcement Interim Final Rule. Department of Health and Human Services. Accessed March 12, 2021 at: https://www.hhs. gov/hipaa/for-professionals/special-topics/hitechact-enforcement-interim-final-rule/index.html

40. HIPAA Administrative Simplification Regulation Text 45 CFR Parts 160, 162, and 164. Department of Health and Human Services. Accessed March 12, 2021 at: https:/www.hhs.gov/sites/default/files/ocr/privacy/hipaa/administrative/combined/hipaa-simplification-201303.pdf?language $=$ es

41. HIPAA and COVID-19. Department of Health and Human Services. Accessed March 12, 2021 at: https://www.hhs.gov/hipaa/for-professionals/special-topics/hipaa-covid19/index.html

42. Audiology \& Speech-Language Pathology Interstate Compact (ASLP-IC). Accessed March 12, 2021 at: https://aslpcompact.com/about/

43. ASLP Interstate Compact Map. Audiology and Speech-Language Pathology Interstate Compact. Accessed March 12, 2021 at: https://aslpcompact. com/compact-map/

44. Andrews E, Berghofer K, Long J, Prescott A, Caboral-Stevens M. Satisfaction with the use of telehealth during COVID-19: an integrative review. Int J Nurs Stud Adv 2020;2:100008

45. Audiology Code List effective 01/01/2021. Centers for Medicare and Medicaid Services. Accessed March 12, 2021 at: https://www.cms.gov/Medicare/Billing/TherapyServices/Downloads/Audiology_Codes.pdf

46. Willink A, Shoen C, Davis K. How Medicare could provide dental, vision, and hearing care for beneficiaries. Issue Brief (Commonw Fund) 2018; 2018:1-12

47. Jilla AM, Johnson CE, Huntington-Klein N. Hearing aid affordability in the United States. Disabil Rehabil Assist Technol 2020(Oct):1-7

48. List of Telehealth Services. Centers for Medicare and Medicaid Services. Accessed March 12, 2021 at: https://www.cms.gov/Medicare/Medicare-General-Information/Telehealth/Telehealth-Codes

49. Medicare Telemedicine Health Care Provider Fact Sheet. Centers for Medicare and Medicaid Services Accessed March 12, 2021 at: https://www.cms. gov/newsroom/fact-sheets/medicare-telemedicine-health-care-provider-fact-sheet

50. Special coding advice during COVID-19 public health emergency (Version 3.1b). American Medical Association Accessed March 12, 2021 at: https://www.ama-assn.org/system/files/2020-05/ covid-19-coding-advice.pdf
51. Social Security Act: Section 1861(11)(3). United States Social Security Administration. Accessed March 12, 2021 at: https://www.ssa.gov/OP_ Home/ssact/title18/1861.htm

52. 2020 MIPS Quality Measures List. Centers for Medicare and Medicaid Services. Accessed March 12, 2021 at: https://qpp-cm-prod-content. s3.amazonaws.com/uploads/763/2020\%20MIPS\% 20Quality\%20Measures\%20List.xlsx

53. Medicare CPT Coding Rules for Audiology Services. American Speech-Language-Hearing Association. Accessed March 12, 2021 at: https://www. asha.org/practice/reimbursement/medicare/Aud_ coding_rules/

54. Medicine. In: CPT Editorial Panel eds.. CPT: Professional Edition. American Medical Association; 2021:718-724

55. H.R. 1587 - To provide certain coverage of audiologist services under the Medicare program, and for other purposes. United States Congress. Accessed March 12, 2021 at: https://www.congress.gov/bill/117th-congress/house-bill/1587?s= $2 \& \mathrm{r}=1$

56. Social Security Act. Sec.. 1905. [42 U.S.C. 1396d (r)(4)]. United States Social Society Administration. Accessed March 12, 2021 at: https://www.ssa. gov/OP_Home/ssact/title19/1905.htm

57. Willink A, Hernando MA, Steege S. Why state Medicaid programs should cover hearing aids for adults. JAMA Otolaryngol Head Neck Surg 2019; 145(11):999-1000

58. State Medicaid \& CHIP Telehealth Toolkit: Policy Considerations for States Expanding Use of Telehealth, COVID-19 Version. Centers for Medicare and Medicaid Services. Accessed March 12, 2021 at: https://www.medicaid.gov/ medicaid/benefits/downloads/medicaid-chip-telehealth-toolkit.pdf

59. 100-16: Medicare Managed Care Manual. Centers for Medicare and Medicaid Services. Accessed March 12, 2021 at: https://www.cms.gov/Regulations-and-Guidance/Guidance/Manuals/Internet-Only-Manuals-IOMs-Items/CMS019326

60. American Speech-Language-Hearing Association. State insurance mandates for hearing aids. Accessed September 3, 2020 at: https://www.asha.org/ advocacy/state/issues/ha_reimbursement/\#: :text= Requires\%20insurers\%20to\%20provide\%20coverage,in\%20the $\% 20$ insured's\%20hearing $\% 20$ status

61. Waddill K. ME payers cover hearing aids, selfinsured companies exempt. Accessed September 23, 2020 at: https://healthpayerintelligence. $\mathrm{com} /$ news/me-payers-cover-hearing-aids-self-insured-companies-exempt

62. Abrams H, Chisolm TH, McArdle R. A costutility analysis of adult group audiologic rehabilitation: are the benefits worth the cost? J Rehabil Res Dev 2002;39(05):549-558 
63. Reed NS, Betz JF, Kucharska-Newton AM, Lin FR, Deal JA. Hearing loss and satisfaction with healthcare: an unexplored relationship. J Am Geriatr Soc 2019;67(03):624-626

64. Chang JE, Weinstein BE, Chodosh J, Greene J, Blustein J. Difficulty hearing is associated with low levels of patient activation. J Am Geriatr Soc 2019; 67(07):1423-1429

65. Chang JE, Weinstein B, Chodosh J, Blustein J. Hospital readmission risk for patients with selfreported hearing loss and communication trouble. J Am Geriatr Soc 2018;66(11):2227-2228 